\title{
Heterogeneous Presentation of Neonatal Hemochromatosis in Dichorionic Twins
}

\author{
Yee Yuet Chee, FHKAM ${ }^{1}$ Siu Chun Mabel Wong, FHKAM ${ }^{1}$ Ming Sum Rosanna Wong, FHKAM ${ }^{1}$ \\ ${ }^{1}$ Department of Paediatrics and Adolescent Medicine, University of \\ Hong Kong, Hong Kong, Hong Kong \\ Am J Perinatol Rep 2018;8:e332-e334. \\ Address for correspondence Yuet Yee Chee, FHKAM, Department of \\ Paediatrics and Adolescent Medicine, University of Hong Kong, 102 \\ Pokfulam Road, Queen Mary Hospital, Hong Kong, Hong Kong \\ (e-mail: yychee@hotmail.com).
}
Abstract
Keywords
- neonatal hemochromatosis
- gestational alloimmune liver disease
- liver failure

Acute liver failure (ALF) in neonates is rare. Although the incidence is reported to be rare, neonatal hemochromatosis (NH) has to be considered as one of the causes of neonatal ALF. We present a pair of dichorionic twin who had a diverse clinical presentation of $\mathrm{NH}$. One twin passed away despite medical treatment with exchange transfusion and intravenous immunoglobulin (IVIg), whereas the other twin suffered from only mildly deranged liver function, which normalized spontaneously. Early identification of liver failure and clinical awareness of this disease entity are essential to its timely diagnosis and treatment. Antenatal management using IVIg prevents the recurrence of $\mathrm{NH}$ in subsequent pregnancies.

\section{Case Report}

\section{Clinical Presentation}

A dichorionic diamniotic male twin was born at 35 weeks of gestation with a birth weight of $1.6 \mathrm{~kg}$ (small for gestational age). The baby presented with recurrent hypoglycemia shortly after birth. Blood tests on the second day of life showed cholestasis (up to $145 \mathrm{umol} / \mathrm{L}$ ), hypoalbuminemia, hyperam- monemia (up to $453 \mathrm{umol} / \mathrm{L}$ ), and coagulopathy, which progressively worsened throughout the first week of life. Work-up for neonatal liver failure was negative for metabolic disease, and surgical and infective causes.

Ferritin level was elevated at 8,397 umol/L. Biopsy of the liver and buccal mucosa was performed. This demonstrated hepatic and extrahepatic iron deposition (-Fig. 1) and confirmed the

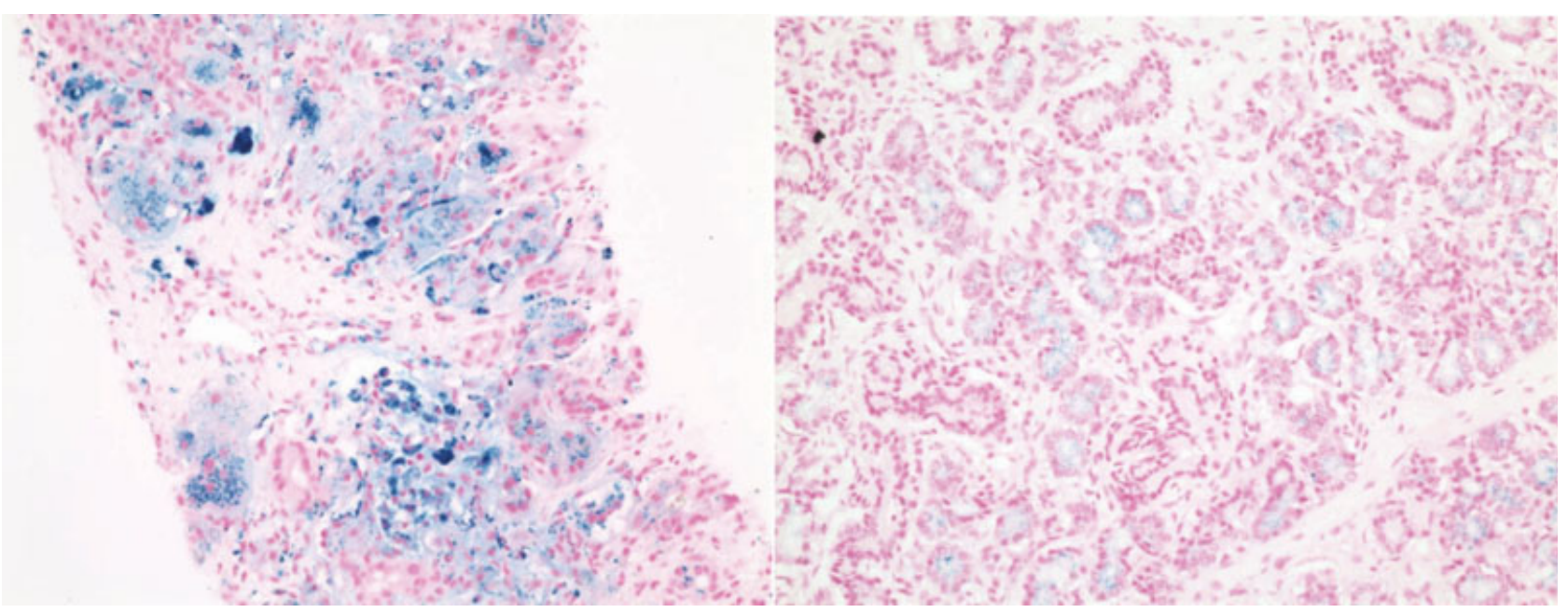

Fig. 1 Liver biopsy showing hepatocellular siderosis (left) and abnormal iron deposition in salivary gland (right), demonstrating iron in blue by Perl's stain.

received

January 31, 2018 accepted after revision June 19, 2018
DOI https://doi.org/

10.1055/s-0038-1675335. ISSN 2157-6998.
Copyright $\odot 2018$ by Thieme Medical Publishers, Inc., 333 Seventh Avenue, New York, NY 10001, USA Tel: +1(212) 584-4662.
License terms

(c) (i) $\ominus$ (\$) 


\begin{tabular}{|c|c|c|c|c|c|c|c|c|c|c|c|c|c|}
\hline & $\begin{array}{l}\infty \\
\frac{\pi}{3} \\
\underline{\underline{z}}\end{array}$ & | & 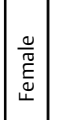 & $\hat{m}$ & 丞 & $\stackrel{\infty}{\sim}$ & 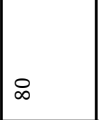 & $\frac{\pi}{z}$ & $\begin{array}{l}\infty \\
m\end{array}$ & $\stackrel{\dot{m}}{\dot{m}}$ & 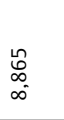 & 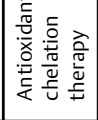 & 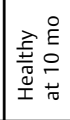 \\
\hline 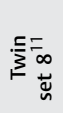 & 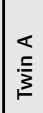 & 怤 & 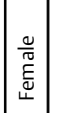 & $\hat{m}$ & 孚 & $\bar{\sigma}$ & r & $\frac{s}{z}$ & $\bar{\sim}$ & $\underset{\sim}{\sim}$ & 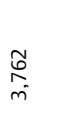 & 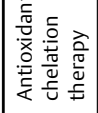 & 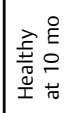 \\
\hline & $\begin{array}{l}\infty \\
\frac{c}{3} \\
\frac{c}{3}\end{array}$ & 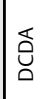 & 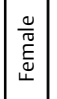 & $\stackrel{m}{m}$ & 丞 & 6 & $\sigma$ & $\frac{1}{z}$ & $F$ & - & 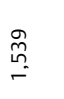 & 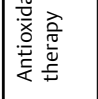 & 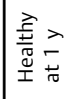 \\
\hline 竞竞 & 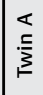 & 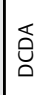 & $\frac{\frac{0}{\pi N}}{2}$ & $\stackrel{m}{m}$ & 孚 & $\overline{\tilde{v}}$ & $\stackrel{m}{=}$ & $\frac{s}{z}$ & $\lesssim$ & $\dot{\dot{f}}$ & 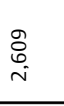 & 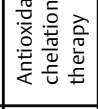 & 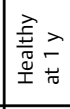 \\
\hline & $\begin{array}{l}\infty \\
\frac{\pi}{3} \\
\underline{\underline{z}}\end{array}$ & U & $\frac{\frac{\omega}{\tilde{N}}}{\Sigma}$ & $m$ & $\bar{i}$ & $\frac{\pi}{z}$ & $\frac{\pi}{z}$ & $\frac{s}{z}$ & in & 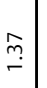 & $\stackrel{\infty}{=}$ & 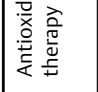 & 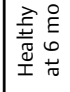 \\
\hline 总总 & 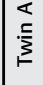 & $\breve{\Sigma}$ & 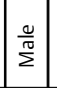 & $m$ & $\stackrel{\leftrightarrow}{\sim}$ & 1 & 1 & 1 & 1 & 1 & 1 & 1 & $\underline{\underline{g}}$ \\
\hline & $\begin{array}{l}\infty \\
\frac{\tilde{n}}{3} \\
\underline{\underline{z}}\end{array}$ & 这 & $\frac{\frac{0}{N \pi}}{\sum}$ & $\stackrel{\sim}{\sim}$ & $\stackrel{9}{\circ}$ & $\stackrel{\mathscr{\sigma}}{\digamma}$ & $\frac{\pi}{z}$ & $\frac{s}{z}$ & $\left|\begin{array}{l}: \\
0\end{array}\right|$ & 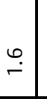 & 岕 & 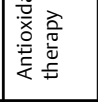 & 产 \\
\hline 雨总 & 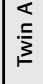 & 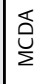 & $\frac{\frac{0}{\tilde{\nu}}}{\frac{\tilde{\nu}}{2}}$ & $\stackrel{\sim}{~}$ & $\infty_{\infty}^{\infty}$ & i & $\frac{\pi}{z}$ & $\frac{s}{z}$ & $\stackrel{\infty}{\sim}$. & $\stackrel{\sim}{\simeq}$ & 等 & 蓉产总 & 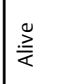 \\
\hline 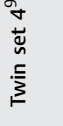 & 造 & $\frac{\pi}{z}$ & $\frac{\frac{0}{\tilde{N}}}{\Sigma}$ & 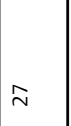 & ๙ิ & g & $\frac{\pi}{z}$ & $\frac{\pi}{z}$ & $\stackrel{\infty}{\circ}$ & $\stackrel{n}{-}$ & $\begin{array}{l}\text { O. } \\
\stackrel{\leftrightarrow}{0} \\
i\end{array}$ & 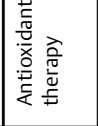 & 妾 \\
\hline & $\begin{array}{l}\infty \\
\frac{n}{3} \\
\underline{3}\end{array}$ & 乡 & 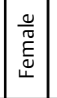 & I & 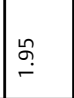 & $\frac{\pi}{z}$ & $\frac{\pi}{z}$ & $\frac{s}{z}$ & $\frac{\pi}{z}$ & $\frac{\pi}{z}$ & $\frac{\pi}{z}$ & $\frac{s}{z}$ & 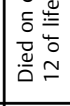 \\
\hline 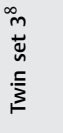 & 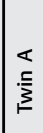 & 乡 & 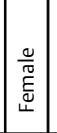 & $\dot{m}$ & $\stackrel{\infty}{\stackrel{\infty}{\Gamma}}$ & 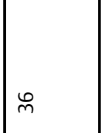 & $\stackrel{9}{-}$ & $\stackrel{m}{m}$ & 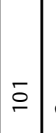 & $m$ & 怘 & 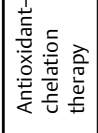 & 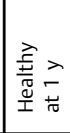 \\
\hline & $\begin{array}{l}\infty \\
\frac{n}{3} \\
\underline{\underline{z}}\end{array}$ & 乡 & $\frac{\frac{0}{\pi}}{\Sigma}$ & $\hat{m}$ & $\stackrel{n}{N}$ & $\stackrel{9}{g}$ & $\bar{\sim}$ & $\stackrel{m}{m}$ & $\approx$ & $\stackrel{\leftrightarrow}{\longrightarrow}$ & 誉 & 总 & 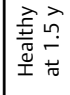 \\
\hline 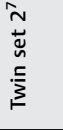 & 迹 & $\breve{\Sigma}$ & $\frac{\frac{0}{\pi N}}{\Sigma}$ & $\hat{m}$ & $\stackrel{\text { g }}{\text { i }}$ & 点 & $\approx$ & ○ิ & $\stackrel{\infty}{\curvearrowright}$ & $\stackrel{\infty}{\sim}$ & 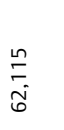 & $\stackrel{U}{\underline{U}}$ & 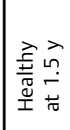 \\
\hline & $\begin{array}{l}\infty \\
\frac{c}{3} \\
\frac{1}{3}\end{array}$ & 遌 & 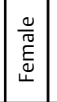 & $\stackrel{m}{m}$ & $\stackrel{\dot{N}}{\mathrm{i}}$ & $\stackrel{\circ}{\circ}$ & $=$ & 庰 & 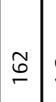 & $\stackrel{\sim}{=}$ & $\begin{array}{l}\bar{D} \\
\tilde{D}_{0} \\
\sigma_{0}\end{array}$ & 总 & 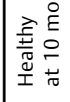 \\
\hline 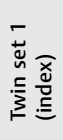 & $\begin{array}{l}\frac{\pi}{2} \\
\frac{\pi}{3} \\
\frac{1}{3}\end{array}$ & 通 & $\frac{\frac{0}{\tilde{N}}}{\sum}$ & $\stackrel{m}{m}$ & $\stackrel{\circ}{\check{r}}$ & $\begin{array}{l}\infty \\
\stackrel{\infty}{m}\end{array}$ & $\stackrel{\text { q }}{\text { f }}$ & I & in & 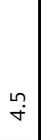 & 佱 & 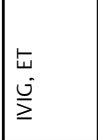 & 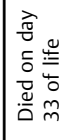 \\
\hline 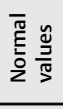 & & & & & & $\underset{\tilde{N}}{\sim}$ & $\stackrel{\circ}{\mathrm{v}}$ & $\begin{array}{l}8 \\
\dot{0} \\
\vee\end{array}$ & $\hat{\hat{\vartheta}}$ & v & 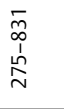 & & \\
\hline & & 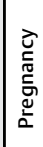 & 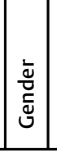 & 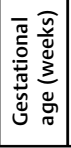 & 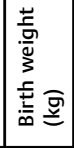 & 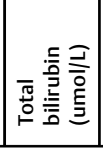 & 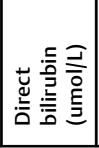 & $\mid \begin{array}{c}\frac{2}{2} \\
\frac{5}{2} \\
\frac{5}{2}\end{array}$ & $\begin{array}{l}2 \\
\frac{2}{2} \\
\frac{5}{4} \\
<\end{array}$ & $\underline{\underline{a}}$ & 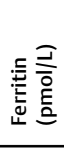 & 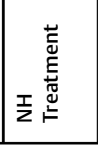 & 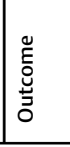 \\
\hline
\end{tabular}


diagnosis of neonatal hemochromatosis $(\mathrm{NH}$; likely due to gestational alloimmune liver disease, GALD). Medical treatment was given with exchange transfusion and intravenous immunoglobulin (IVIg). However, he failed to respond to medical treatment and developed worsening liver failure. Liver transplantation was considered but deemed not an option due to the low body weight and unavailability of living-related liver donor. After extensive discussion with the parents, the decision for redirection of care was made. The baby was electively extubated and eventually succumbed on day 33 of life.

On the contrary, the other twin girl was born with a birth weight of $2.4 \mathrm{~kg}$ and suffered only from mildly deranged liver function only. Her liver function test showed mildly elevated liver enzymes (peak aspartate aminotransferase [AST] of 371 U/L and alanine aminotransferase [ALT] of $162 \mathrm{U} / \mathrm{L}$ at around 3 weeks of life) and conjugated bilirubin (11 umol/L), with normal ammonia level and clotting profile all along. Metabolic, surgical, and infective work-ups were negative. Ferritin level was high at $9,801 \mathrm{umol} / \mathrm{L}$. Liver function test subsequently normalized spontaneously upon follow-up.

Family was counseled on the importance of antenatal treatment with IVIg in future pregnancies to prevent the recurrence of $\mathrm{NH}$.

\section{Discussion}

Although neonatal liver failure is rarely encountered, one of the most important diagnoses to consider is $\mathrm{NH}$. $\mathrm{NH}$ is a rare condition. The exact incidence of the disorder is unknown. Fetal liver injury causes disturbed fetal iron homeostasis, resulting in fetal iron overload. $\mathrm{NH}$ is characterized by severe liver injury with the accumulation of iron in hepatic and extrahepatic tissues. The most common cause of fetal liver injury leading to the $\mathrm{NH}$ phenotype is a gestational alloimmune disorder called GALD., ${ }^{1,2}$ It results from the transplacental transfer of maternal immunoglobulin $\mathrm{G}(\operatorname{IgG})$ directed against an antigen on the fetal hepatocyte, with fetal complement activation and formation of membrane attack complex, resulting in fetal hepatocyte injury and death (with congenital cirrhosis and siderosis of extrahepatic tissues). Once a woman has become sensitized, transplacental passage of IgG can occur in subsequent pregnancy, causing immune-mediated liver injury in the fetus.

Diagnosis of NH is by the demonstration of iron accumulation in the extrahepatic tissues, usually through the biopsy of oral mucosal salivary glands or using T2-weighed magnetic resonance imaging (MRI) demonstrating the accumulation of iron in the pancreas, heart, or adrenal glands. ${ }^{1}$ Antibodies to C5b-9 complex, a neoantigen created during the activation of terminal complement cascade, are used to demonstrate the accumulation of membrane attack complex in liver biopsy. ${ }^{2}$ However, this immunohistochemical staining for C5b-9 complex is not available in our locality.

Treatment for NH includes exchange transfusion (by removing existing reactive antibodies) and IVIg (blocking antibody action and interfering with complement activation). ${ }^{3,4}$ Survi- val with medical treatment (without liver transplantation) is reported to be at around $75 \% .{ }^{4}$ If medical treatment fails, liver transplantation remains to be the last therapeutic option.

$\mathrm{NH}$ presentation could be quite heterogeneous, as shown in this pair of twins. The twin boy was being affected antenatally with growth restriction and early presentation with hypoglycemia within few hours after birth followed by liver failure. Without the frank presentation of liver failure in one of the index twin, the other twin would have been managed as a case of neonatal hepatitis, and the diagnosis of NH would be missed. With antenatal IVIg treatment, outcome of future pregnancy in our index family is expected to be good., ${ }^{5,6}$

- Table 1 summarizes the clinical characteristics of published cases of twins pregnancy affected by $\mathrm{NH}$ in the literature. $^{7-11}$

\section{Conclusion}

In conclusion, a high index of suspicion of $\mathrm{NH}$ in babies presenting with cholestasis and deranged liver function is important so as to facilitate its early diagnosis and management. It has a high recurrence in subsequent pregnancies, and antenatal IVIg treatment can greatly reduce this chance.

Conflicts of Interest

All contributing authors declare no conflicts of interest.

\section{References}

1 Whitington PF. Gestational alloimmune liver disease and neonatal hemochromatosis. Semin Liver Dis 2012;32(04):325-332

2 Heissat S, Collardeau-Frachon S, Baruteau J, et al. Neonatal hemochromatosis: diagnostic work-up based on a series of 56 cases of fetal death and neonatal liver failure. J Pediatr 2015;166(01):66-73

3 Lopriore E, Mearin ML, Oepkes D, Devlieger R, Whitington PF. Neonatal hemochromatosis: management, outcome, and prevention. Prenat Diagn 2013;33(13):1221-1225

4 Rand EB, Karpen SJ, Kelly S, et al. Treatment of neonatal hemochromatosis with exchange transfusion and intravenous immunoglobulin. J Pediatr 2009;155(04):566-571

5 Whitington PF, Hibbard JU. High-dose immunoglobulin during pregnancy for recurrent neonatal haemochromatosis. Lancet 2004;364(9446):1690-1698

6 Whitington PF, Kelly S. Outcome of pregnancies at risk for neonatal hemochromatosis is improved by treatment with high-dose intravenous immunoglobulin. Pediatrics 2008;121(06):e1615-e1621

7 Midorikawa H, Mizuochi T, Okada JI, Hisano T. Disparate clinical findings in monochorionic twins with neonatal hemochromatosis. Pediatr Int 2017;59(11):1215-1216

8 Korkmaz L, Baştuğ O, Daar G, Doğanay S, Deniz K, Kurtoğlu S. Neonatal hemochromatosis in monochorionic twins. J Neonatal Perinatal Med 2015;8(04):413-416

9 Isa HM, Mohamed AM. Neonatal hemochromatosis. Case series from Bahrain. Saudi Med J 2013;34(12):1274-1280

10 Vanden Eijnden S, Hassoun M, Donner C, et al. Iron overload in gestational alloimmune liver disease: still more questions than answers. Prenat Diagn 2012;32(08):810-812

11 Ekong UD, Kelly S, Whitington PF. Disparate clinical presentation of neonatal hemochromatosis in twins. Pediatrics 2005;116(06): e880-e884 